\title{
Correspondence
}

\section{Anaesthesia and past use of LSD}

To the Editor:

We report the case of a 43-yr-old lady who was admitted to the Day Surgery Unit for release of her carpal tunnel retinaculum. During the preoperative visit, she reported no intercurrent illnesses, drug therapy or allergies. She did say, however, that she was frightened of general anaesthesia, since she had experienced terrifying dreams during surgery under general anaesthesia on three occasions during the previous ten years. On further questioning, she admitted that she had used lysergic acid diethylamide (LSD) during the late 1960's, the last occasion being 1968 when she had experienced characteristic hallucinations. She had not experienced hallucinations in the ensuing years, except on the surgical occasions mentioned.

One of the three previous operations had been performed at our hospital and the anaesthetic record was checked. On that occasion she had received papaveretum and hyscine as a premedication, and anaesthesia had been induced with thiopentone, and maintained with oxygen, nitrous oxide and halothane. The patient was certain she had suffered frightening dreams on that occasion, although there was no record of it in the hospital notes. Despite this history and her fear, she expressed a clear preference for general over regional anaesthesia.

Without making any assurances, it was explained that all would be done to try to prevent her from having distressing dreams in a way consistent with day care anaesthesia. No premedication was prescribed. In the anaesthetic room she was given metoclopramide $10 \mathrm{mg}$ and midazolam $5 \mathrm{mg} i v$, immediately followed by fentanyl 50 $\mu \mathrm{g}$ and propofol $150 \mathrm{mg} i v$ for induction. A laryngeal mask airway was inserted and anaesthesia was maintained by spontaneous ventilation with oxygen, nitrous oxide $\left(\mathrm{FlO}_{2}=0.33\right)$ and isoflurane $2 \%$. The blood pressure, $\mathrm{ECG}$, and pulse oximeter recordings were unremarkable throughout. She recovered in a quiet, darkened room. On questioning $20 \mathrm{~min}$ after waking in the recovery room, she reported that she had had no bad dreams or hallucinations but had experienced the sensation of "being covered with leaves." She was fit for discharge in the company of her husband some three hours later.

The most recent figures from the South West Region Drug Problem Database, Bristol, UK (Boulton, personal communication) showed that $6.5 \%$ of their new clients were using LSD. It is more popular than other commonly used hallucinogens whose quoted incidence of clients are: ketamine $0.1 \%$ (super-K/vitamin K. ${ }^{\text {) }}$ ), psilocybin and psilocin $0.6 \%$ (the active alkaloids in the Mexican "magic mushroom"), and 3,4 methylenedioxymethamphetamine "MDMA" $1 \%$ (ecstasy). The effects of the concurrent ingestion of LSD on anaesthesia are well described. ${ }^{2-4}$ The long-term effects of the past use of LSD are largely unknown. We wonder if the hallucinations experienced by our patient during anaesthesia were due to her LSD intake many years before. We would be interested to know if others have had experience anaesthetising patients who are past users of phencyclidine-derived drugs.

\section{Geoffrey N. Morris MRCGP FRCA}

Patrick T. Magee MSc FRCA

Anaesthetic Department

Royal United Hospital

Combe Park

Bath BA1 3NG

Avon, UK

\section{REFERENCES}

1 Jansen $K L R$. Non-medical use of ketamine (Editorial). BMJ 1993; 306: 601-2.

2 Jenkins $L C$. Anaesthetic problems due to drug abuse and dependence. Can Anaesth Soc J 1972; 19; 461-77.

3 Wood PR, Soni $N$. Anaesthesia and substance abuse. Anaesthesia 1989; 44: 672-80.

4 Elliott $H W$. Effects of street drugs on anesthesia. International Journal of Clinical Pharmacology \& Biopharmacy $1975 ; 12: 134-40$.

\section{A new solution to fibreoptic intubation in the presence of blood and secretions}

To the Editor:

The role of the laryngeal mask airway (LMA) as an aid to fibreoptic intubation has been well defined. ${ }^{1-5}$ However, the role of the LMA as a protective guide to fibrescopy in the presence of blood, vomitus or secretions in the oral cavity has not been reported earlier.

A 67-yr-old apprehensive man with an unstable fracture of the sixth cervical vertebrae was scheduled for pos- 
terior cervical fusion of $\mathrm{C}_{5-6}$ as an emergency procedure. For fear of moving the cervical spine and causing secondary neurological damage, it was decided to perform nasal fibreoptic intubation under general anaesthesia. After instilling nasal decongestant, anaesthesia was induced with halothane and $100 \%$ oxygen. On reaching an adequate depth of anaesthesia, a well lubricated 7.5 $\mathrm{mm}$ internal diameter (ID) nasal endotracheal tube (ETT) was passed via the nostril into the hypopharynx. A fibreoptic bronchoscope (FB) was passed via the ETT. On emerging from the ETT, the view was found to be obscured by blood (secondary to traumatic passage of ETT) despite repeated suctioning. It was decided to abandon nasal intubation and perform oral fibreoptic intubation assisted by a Berman airway. However, the slit in the Berman airway could not prevent the tip of the FB from soiling with blood and secretion. Multiple attempts failed to visualize the vocal cords. At this stage, our modified size \#4 LMA (MLMA) ${ }^{1,2}$ with a split along its shaft extending to the inflatable cuffed portion was inserted with ease and the cuff inflated. The FB with premounted 8 mm ID cuffed ETT was passed through the MLMA. With minimal manipulation the FB was guided towards the vocal cords. At this stage succinylcholine $50 \mathrm{mg} i v$ was given and the trachea entered. The MLMA was now disengaged via its split surface and removed. The ETT was advanced over the FB into the trachea uneventfully.

Fibrescopy may be difficult when blood, vomitus, or secretions obscure the view. We observed that the Berman airway as a protective guide to $\mathrm{FB}$ was unsuitable for fibrescopy in such a situation. The edges of the slit in this airway are separated to prevent blood and secretion from soiling the tip of the FB. On the contrary, the split edges of the MLMA lie in close approximation to each other thereby providing a good protective sheath to the FB even in the presence of blood and secretion in the oral cavity.

\author{
Mohammed Maroof MD \\ Rashid M. Khan MD \\ Augustine Bonsu FFARCS \\ Hyder S. Raza MD \\ Department of Anaesthesiology \& Surgery \\ King Fahad National Guard Hospital \\ PO Box 22490, Riyadh \\ Kingdom of Saudi Arabia
}

\section{REFERENCES}

1 Maroof M, Khan RM, Siddique MSK. Modified laryngeal mask as an aid to fiberoptic endotracheal intubation (Letter). Acta Anaesthesiol Scand 1993; 37: 124.

2 Maroof M, Khan RM, Siddique MSK, Bhatti TH, Hus- sain $H$. Fiber-optic intubation through a modified laryngeal mask. Anesthesiology 1992; 77: A510.

3 Benumof $J L$. Use of the laryngeal mask airway to facilitate fiberscope-aided tracheal intubation (Letter). Anesth Analg 1992; 74: 313-5.

4 Tuck $M$, Phillips $R$, Corbett J. LMA for fibreoptic bronchoscopy (Letter). Anaesth Intensive Care 1991; 19: 475-3.

5 Smith JE, Sherwood NA. Combined use of laryngeal mask airway and fibreoptic laryngoscope in difficult intubation (Letter). Anaesth Intensive Care 1991; 19: 471-2.

\section{Myasthenia gravis and regional anaesthesia}

To the Editor:

This case report shows how regional anaesthesia is not always free of complications in myasthenic patients.' A 65-yr-old, 87-kg woman was admitted for debridement of a palmar abscess. Myasthenia gravis (MG) had been diagnosed two years before, and for six months had been in stage IIB $^{2}$ and had an FVC of $950 \mathrm{ml}$. She received pyridostigmine $600 \mathrm{mg}$ and prednisone $70 \mathrm{mg}$ om po. Regional anaesthesia was proposed and a right-axillary brachial plexus block was carried out with the use of a neurostimulator and $38 \mathrm{ml}$ mepivacaine $1,5 \%$ were injected. No sedation was administered. Forty-five minutes after the block, the patient suffered a respiratory weakness which required transitory assisted ventilation with face mask and was reversed with small doses of pyridostigmine up to $4 \mathrm{mg} i$. Two hours after surgery, in the recovery room, and at the time of administration of cloxacillin $(500 \mathrm{mg} i v)$ the patient again suffered respiratory depression which did not recover with neostigmine $1 \mathrm{mg}$ $\dot{i} v$ and required orotracheal intubation and mechanical ventilation. The patient was transferred to the ICU and was weaned from IPPV three days later. She was discharged after 25 days with recovery to MG stage IIB.

Several factors may have played a role. First, although ester local anaesthetics may affect neuromuscular transmission in patients receiving anticholinesterase therapy, ${ }^{3}$ we used mepivacaine, an amide local anaesthetic without effect on neuromuscular transmission. Second, stress may have contributed to the MG crisis. She did not receive sedation because diazepam $i v$ is not advisable in patients with limited respiratory reserve. ${ }^{3}$ Third, antibiotics are the best known drugs involved in the development of a myasthenic crisis. However, cloxacillin has not yet been specifically implicated. Postoperative mechanical ventilation may be required in myasthenic patients and the risk factors have been well described. ${ }^{5}$ However, none were found in the reported case. Therefore, preoperative evaluation 